\title{
An Analysis of the Association Between Work Stress and Health Behaviours in Korean and Japanese Ageing Studies: a Cross- sectional Study
}

\author{
Taozhu Cheng \\ Peking University \\ Jing Guo ( $\square$ jing624218@163.com ) \\ Peking University \\ Pikhart Hynek \\ University College London
}

\section{Research Article}

Keywords: Work stress, Effort-reward Imbalance, Health Behaviours, Smoking, Drinking

Posted Date: December 3rd, 2021

DOI: https://doi.org/10.21203/rs.3.rs-1100342/v1

License: (c) (i) This work is licensed under a Creative Commons Attribution 4.0 International License. Read Full License 


\section{Abstract}

Background and Objectives: Work stress is a risk factor that may be partially responsible for increased cardiovascular morbidity and mortality. One of the proposed pathways is through unhealthy behaviours. As limited research has focused on the association between work stress and health behaviours in Asian countries, this research aims to explore the effect of work stress on the two health behaviours among employees aged 45 or above in Korea and Japan.

Methods: This cross-sectional study based on baseline data from the Korean Longitudinal Study of Aging (KLoSA,2006) and Japanese Study of Aging and Retirement (JSTAR,2007\&2009) used logistic regression and multinomial logistic regression to investigate the association between work stress represented by the short version of the effort-reward imbalance (ERI) model and smoking (binary current smoking) and drinking (categorical volume of alcohol). In addition, the statistical power was over $80 \%$ for odds ratios (ORs) greater than 1.3 in Korea and 1.6 in Japan. Moreover, this research additionally examines the potential interaction between ERI and gender.

Results: Smoking and drinking were significantly associated with the ER ratio in the Korean analysis $(\mathrm{N}=3,478)$. After the model was fully adjusted, the OR $(95 \% \mathrm{Cl})$ and RRR $(95 \% \mathrm{Cl})$ were $1.45(1.17-1.80)$ and $1.43(1.09-1.90)$, respectively. In Japan $(\mathrm{N}=1,504)$, smoking was associated with the ER ratio (OR 1.37 (1.00-1.87)); however, drinking was not. No statistically significant interaction was found between ERI and gender ( $p$ value of 0.82 in Korea and 0.19 in Japan).

Conclusions: The results of this study showed that work stress was statistically significantly associated with both health behaviours in the Korean sample and with smoking in Japan. These results potentially suggest the integration of long working time reduction health promotion programmes in these two Asian countries.

\section{Background}

In the last few decades, many public health studies have highlighted the necessity of studying unhealthy behaviours such as smoking, drinking, poor diet and sedentary lifestyles [1, 2]. Scholars have observed that smoking, binge drinking, less exercise and poor diet contribute significantly to the high level of morbidity and mortality witnessed in both developed and developing countries $[1,3,4]$. Some risk factors, such as work stress, associated with unhealthy behaviours have not been studied extensively in the past $[1,5]$. Even though moderate work stress can motivate people to become more productive, excessive or unmanageable stress may increase their risks of unhealthy behaviours [6]. Research has even shown that when people are not satisfied with their work or do not receive the desired rewards for their efforts, they are more likely to experience work stress [7].

\section{Two models for work stress evaluation}

Two models that are widely used in many epidemiological studies to evaluate the level of work stress include Karasek's Job Demand-Control (JDC) model and Siegrist's Effort-Reward Imbalance (ERI) model [8-14]. The JDC model measures the magnitude of work-related stress from job demand and job control dimensions [9]. The model postulates that the most stressed people are those with high job demands combined with low work control $[9,10]$. However, at the core of the ERI model, there is the principle of the work contract and social reciprocity [14]. This model predicts that the combination of high efforts and low rewards would significantly increase negative emotions and a high level of work stress [15].

\section{Reasons for studying the association between work stress and health behaviours in Korea and Japan}

Previous research has indicated that health behaviours, including smoking, alcohol consumption, diet and exercise, are likely to be associated with chronic and cardiovascular diseases [16]. In addition, most of the existing studies have focused on European and North American countries, and only a few have examined the association between job stress and health behaviours in East Asian countries $[1,5]$.

A paper based on two Finnish cohort studies utilised the ERI model to examine the relationship between work stress and smoking and found that highly stressed people were more likely to smoke [2]. Another US study, using the job strain model, produced a similar result and concluded that high strain jobs were positively associated with smoking intensity [17]. In terms of drinking, Siegrist and Rödel, in their meta-analysis of 18 articles, investigated the association between work-related stress and alcohol 
consumption [6]. They indicated that most of the existing articles have used the JDC model to evaluate work stress, while few articles have used the ERI model [6]. Although a variety of cross-sectional studies failed to determine the association between workrelated stress and heavy episodic drinking, some European studies found that work-related stress contributed to chronic heavy drinking and alcohol addiction [18-20].

Middle-aged and older workers in the Asian region are particularly vulnerable to work-related stress [21, 22]. Because of this and lack of relevant policies and welfare systems guaranteeing the rights of employees in Asia, it is predicted that work-related stress might have a more serious impact on employees in East Asian countries than in Western countries [21, 22]. Two developed countries with similar economic development patterns, Japan and Korea, have witnessed an increased rate of work-related deaths in the last three decades $[7,23]$.

In Korea and Japan, evidence from the analysis of the relationships between work-related stress and health behaviours is limited [24-27]. Kawakami and Haratani pointed out that compared to some European countries, Japanese people felt less satisfied with their jobs, thereby making them more vulnerable to work-related stress [25]. In a Korean cohort study, job security was negatively associated with smoking status among people aged 20-59 [26]. Similarly, in a cross-sectional study conducted in Japan, a considerable number of nurses with high job strains depended on heavy smoking [27].

Additionally, Japan and South Korea have some similarities when exploring the association between work stress and healthy behaviour; however, no literature has compared the two countries simultaneously. Several Japanese and Korean studies found that a gender difference might exist in the association between work stress and various health outcomes $[2,24,25,28]$. Lack of intrinsic work rewards and uncertainty about the future contributed to unhealthy behaviours more seriously in males than in females [28, 29]. Moreover, existing evidence suggests that the role of work stress on health behaviours in Japan is similar to that in Korea. According to different cohort and cross-sectional studies, work stress was negatively associated with vegetable intake and positively associated with high calorie intake [30-32]. The results from two Japanese occupational cohort studies showed that high job strain and ER ratio were modestly related to physical inactivity [33,34]. Previous studies also found that age, gender, education level, marital status, occupational grade, socioeconomic status and working time might be covariates that need to be controlled for when studying the relationship between work-related stress and health behaviours in Korea and Japan [2, 25, 26, 35].

\section{Research gaps in work stress and health behaviours}

In summary, past Japanese and Korean work-stress research focused on the relationship between work-related stress and individual health behaviours in some specific occupations, but they had yet to look at several health behaviours in the same analysis in general population samples [33]. Thus, this paper focuses on the association between work stress and two unhealthy behaviours, smoking and heavy alcohol consumption, in Korea and Japan by using two well-known ageing datasets, JSTAR and KLoSA $[6,36]$. To focus on a potentially more vulnerable population, the target population of this research is middle-aged and older workers aged 45 years and older in Korea and Japan [37]. To provide a comparative evaluation of work stress in these two potentially different socioeconomic and sociocultural contexts, this study uses the ERI model to assess work-related stress. The short form of ERI used in the KLoSA and JSTAR datasets, previously used and partially validated by Siegrist et al, will be used to measure the ERI model $[9,37,38]$. The Methodology section will provide further details of the variables used in the analysis.

\section{Aims, Objectives and Hypotheses}

This study aims to apply the ERI model to evaluate work-related stress and explore its association with the prevalence of smoking and drinking in Korea and Japan among working participants aged 45 years or more. Most importantly, this research aims to examine whether work stress is positively associated with smoking and higher levels of drinking after adjustment for a wide range of available covariates. The study has three objectives: (1) to examine the association between ERI and health behaviours in KLoSA and JSTAR, (2) to investigate the potential interactions between ERI and gender, and (3) to compare results from Korea and Japan and to identify any potential differences in findings.

\section{Methods}

\section{Study design}


Korean data and Japanese data were collected from the Korean Longitudinal Study of Aging (KLoSA) and the Japanese Study of Aging and Retirement (JSTAR), respectively [36, 39]. The KLoSA study was based on the random selection of men and women aged 45-98 in South Korea, excluding Jeju Island. The baseline data were obtained in 2006, and Computer Assisted Personal Interviewing (CAPI) was employed to ask questions related to work stress and health behaviours. The KLoSA follow-up surveys were then conducted every two years. Because of the large number of missing outcome variables in the follow-up waves, it was decided that this study would focus on cross-sectional analysis using 2006 data (wave1).

The JSTAR survey was conducted by the Research Institute of Economy, the Research Institute of Economy, Trade and Industry Trade and Industry (RIETI), Hitotsubashi University, and the University of Tokyo [36]. This survey focused on men and women aged 50-78 in 2007. According to the JSTAR first results report, the data quality was evaluated by comparing the JSTAR database with the 2005 Japanese census data. JSTAR has a high response rate in terms of the Japanese standard; however, JSTAR datasets have various limitations, such as changing the questionnaire between waves [36]. Because of this, some variables are missing in different waves. Siegrist et al. pointed out that JSTAR data were not of enough quality for the longitudinal analysis of work stress, as many people dropped out in later waves [9]. Hence, this project uses the baseline JSTAR data to perform cross-sectional analyses. The data from 5 cities (Adachi, Kanazawa, Shirakawa, Sendai, and Takikawa) were collected in 2007, with an additional two cities (Tosi and Naha) obtained in 2009.

Overall, as KLoSA is a much larger study and past literature suggests that it is of better quality than JSTAR [36, 39], the present study will mainly focus on Korean results. Korean results will then be compared with Japanese results. Both studies were approved by relevant ethical committees in both countries, and all participants signed informed consent for participation in the study.

\section{Study sample}

Figures 1 and 2 present the analytical sample selection in this study. Responders who worked at wave 1 in $\mathrm{KLoSA}(\mathrm{N}=3,478)$ or in $\operatorname{JSTAR}(\mathrm{N}=1,504)$ without missing data were included in the analytical sample. A total of 492 participants were excluded from the analysis due to missing data, which accounted for $12.4 \%$ of the total workers in the Korean baseline sample. According to the same inclusion and exclusion criteria, approximately $53.5 \%(\mathrm{~N}=1,504)$ of responders could be used from a Japanese sample. In summary, nearly $87.6 \%$ of the Korean eligible sample was analysed, while only approximately half of the eligible Japanese sample was included in the analysis.

\section{Measurements}

\section{ERI evaluation}

The ERI, the exposure of this project, was measured with three questions in KLoSA and six questions in JSTAR. The original ERI questionnaire consists of 17 items, 6 of which measure "efforts", and the remaining items measure "rewards" [40]. Because of the limitations of the existing data, only one item is available for evaluating the effort dimension, while two items are available for assessing the reward dimension ("ERI [1+2]") in Korea. In Japan, two and four questions were used to measure "efforts" and "rewards" ("ERI [2+4]"), respectively. In 2008, Siegrist et al. demonstrated in their study that the short version and the long version of the ERI model had similar properties [9]. Hence, this project used the short version to evaluate work stress in a Japanese sample [40]. In this way, the results from the analysis using a shorter version (" $1+2$ ") will be directly comparable between Korean and Japanese samples.

Each item in the model was answered using a 4-point Likert scale. Higher scores indicate higher efforts, while lower scores reflect more work-related stress caused by lower occupational rewards [40]. The ER ratio is calculated by adding the score of the effort and then dividing the value by the total score of reward, adjusted for the different number of items (correction factor), which is 0.5 in the three-item ERI model and six-item ERI model. Then, the categorical ERI is obtained by dividing continuous ERI into tertiles. Individual questions available in both datasets are shown in Table 1, with questions requiring reverse scoring marked with an asterisk. 
Table 1

Questions related to ERI measurement

\begin{tabular}{|c|c|c|}
\hline & KLoSA & JSTAR \\
\hline \multirow[t]{2}{*}{ Effort } & $\begin{array}{l}\text { *My job requires lots of physical } \\
\text { effort. }\end{array}$ & *My current job involves physical labour. \\
\hline & $\mathrm{N} / \mathrm{A}$ & *I have a lot of work and always feel time pressure. \\
\hline \multirow[t]{4}{*}{ Reward } & *l feel my job is secure. & $\begin{array}{l}\text { Do you think it is likely that you could lose your current job for a reason other } \\
\text { than retirement? }\end{array}$ \\
\hline & $\begin{array}{l}\text { *I am satisfied with current } \\
\text { wage. }\end{array}$ & $\begin{array}{l}\text { *Considering the effort I put in and the results I produce, I am satisfied with my } \\
\text { current pay. }\end{array}$ \\
\hline & $\mathrm{N} / \mathrm{A}$ & *I receive appropriate evaluation on my work from co-workers. \\
\hline & $\mathrm{N} / \mathrm{A}$ & *When I have problems doing my work, colleagues give me advice and help me. \\
\hline
\end{tabular}

\section{Health behaviours}

The main focus of the paper in terms of health behaviours is smoking and drinking. Used as a binary outcome in Korea, smoking was assessed by the question "Do you smoke cigarettes now?" Participants who answered "yes" to the question were classified as current smokers, and those whose response was "No" were considered non-smokers. In Japan, participants were asked, "Do you regularly use tobacco, or did you use it in the past?" Participants were given three options: (1) Yes, I smoke now; (2) I smoked in the past, but I have quit; (3) No, I have never smoked regularly. To ensure comparability between the two countries, participants who chose Option (1) were regarded as current smokers, and those who selected (2) or (3) were classified as non-smokers.

Drinking was used as a categorical outcome in the analysis. First, the weekly ethanol intake was calculated by multiplying the weekly drinking frequency of different drinks by their alcohol content. Next, according to the criteria of different drinking levels among men and women, this research classified individuals in Korea and Japan into three groups: non-drinkers, moderate drinkers, and heavy drinkers [25]. Males who drank between 0 210 g ethanol per week ( $\mathrm{g} / \mathrm{wk}$ ) were considered moderate drinkers, and those who consumed more than $210 \mathrm{~g} / \mathrm{wk}$ were regarded as heavy drinkers. Similarly, females who drank approximately $0 \sim 140 \mathrm{~g} / \mathrm{wk}$ and more than $140 \mathrm{~g} / \mathrm{wk}$ were considered moderate drinkers and heavy drinkers, respectively [41].

\section{Covariates}

All available covariates were categorised as demographic, social and socioeconomic, and work-related characteristics. The demographic variables included age and gender. Age was divided into 5-year age groups. The social variables included education and marital status. In each country, education was classified into four categories. In Korea, it was classified into elementary schools, middle schools, high schools and universities; in Japan, it was categorised as elementary and middle schools, vocational schools, high schools, and universities. Marital status was classified into five categories (married, separated, divorced, widowed, and never married) in Korea but was only available in two categories (married/not married) in Japan.

The work-related variables refer to the working position and weekly working hours. In both countries, the working position was classified as non-supervisor, supervisor and self-employed. Participants were asked "How many hours do you work per week on average?" to estimate weekly working hours.

\section{Analytical strategy}

This study employed the number (\%) and mean (SD) for all variables of interest to describe the characteristics of the analytical sample. The associations between exposure (categorical ER-ratio) and outcomes (smoking and drinking) were examined in both countries separately. Given that smoking is a binary variable, logistic regression was used to explore the relationship between ERI and the prevalence of smoking, and odds ratios (ORs) were estimated. Multinomial logistic regression and relative risk ratios (RRRs) were used to evaluate the association between ERI and drinking. In both analyses, the associations between ERI and two 
outcomes were analysed in the same order of adjustment. For all the analyses, four adjusted models were fitted: (Model 1) adjusted for age; (Model 2) Model 1 + gender; (Model 3) Model 2 + education, marital status; and (Model 4) Model 3 + working position, working hours.

Considering that differences might be observed in the healthy behaviours of men and women, likelihood-ratio tests were performed to examine the interactions between ERI and gender. The goodness of fit indices of the regression models, including and excluding the corresponding interaction terms, were compared. (See Supplementary Table 1 and Table 2, Additional File 1).

All the analyses mentioned above were conducted in STATA 15.1.

\section{Results}

\section{Characteristics of samples in Korea and Japan}

Table 2 describes both analytical samples. The mean age of respondents in the Korean sample was 55.6 years (SD=8.3 years), while that of the Japanese sample was 59.2 years ( $S D=6.1$ years). More than half of the participants had at least a high school education in both Korea (53.3\%) and Japan (70.1\%). A large proportion of subjects (Korea 88.6\%, Japan 83.4\%) were married. In both samples, men had a higher working position and were more likely to be self-employed than women.

The prevalence of smoking was $32.2 \%$ in Korea and $30.7 \%$ in Japan. In both countries, the prevalence of smoking was higher among men (Korea: 44.5\%; Japan: 39.9\%) than among women (Korea: 3.6\%; Japan: $13.7 \%$ ). While the prevalence of male heavy drinkers was $21.1 \%$ in Korea and $43.0 \%$ in Japan, it was $3.2 \%$ in Korea and $12.9 \%$ in Japan among women. 
Table 2

Characteristics of the cross-sectional sample in Korea and Japan

\begin{tabular}{|c|c|c|}
\hline \multirow[t]{2}{*}{ Variables } & Korea & Japan \\
\hline & Number(\%) & Number(\%) \\
\hline Sample & 3,478 & 1,504 \\
\hline \multicolumn{3}{|l|}{ Age } \\
\hline years mean (SD) & $55.6(8.3)$ & $59.2(6.1)$ \\
\hline 45-49years & $1,055(30.3)$ & N/A \\
\hline 50-54years & $787(22.6)$ & $392(26.1)$ \\
\hline 55-59years & $596(17.1)$ & $513(34.1)$ \\
\hline 60-64years & $444(12.8)$ & 296(19.7) \\
\hline 65-69years & $358(10.3)$ & $191(12.7)$ \\
\hline >70years & $238(6.8)$ & $112(7.5)$ \\
\hline \multicolumn{3}{|l|}{ Gender } \\
\hline male & $2,431(69.9)$ & $977(65.0)$ \\
\hline female & $1,047(30.1)$ & $527(35.0)$ \\
\hline \multicolumn{3}{|l|}{ Education } \\
\hline elementary & $988(28.4)$ & \multirow[t]{2}{*}{$330(21.9)$} \\
\hline middle & 635(18.3) & \\
\hline vocational school & $\mathrm{N} / \mathrm{A}$ & $120(8.0)$ \\
\hline high & $1,281(36.8)$ & $715(47.5)$ \\
\hline college/university & $574(16.5)$ & $339(22.5)$ \\
\hline \multicolumn{3}{|l|}{ Marital status } \\
\hline married & $3,080(88.6)$ & $1,255(83.4)$ \\
\hline separated & $36(1.0)$ & N/A \\
\hline divorced & $90(2.6)$ & N/A \\
\hline widowed & $238(6.8)$ & $\mathrm{N} / \mathrm{A}$ \\
\hline never married & $34(1.00)$ & $249(16.6)$ \\
\hline \multicolumn{3}{|l|}{ Working position } \\
\hline non-supervisor & $1,366(39.3)$ & $994(66.1)$ \\
\hline supervisor & $409(11.8)$ & 101(6.7) \\
\hline self-employed & $1,703(49.0)$ & $409(27.2)$ \\
\hline \multicolumn{3}{|l|}{ Working hour } \\
\hline hours per week(SD) & $48.5(18.3)$ & 41.7(16.4) \\
\hline \multicolumn{3}{|l|}{ Location } \\
\hline Seoul & $536(15.4)$ & $\mathrm{N} / \mathrm{A}$ \\
\hline
\end{tabular}




\begin{tabular}{|lll|}
\hline Variables & Korea & Japan \\
\cline { 2 - 3 } & Number(\%) & Number(\%) \\
\hline other places & $2,942(84.6)$ & N/A \\
\hline ERI(1+2) & 3,478 & 1,504 \\
\hline lowest tertile & $1,611(46.3)$ & $543(36.1)$ \\
\hline middle tertile & $1,001(28.8)$ & $579(38.5)$ \\
\hline upper tertile(ERI) & $866(24.9)$ & $382(25.4)$ \\
\hline ERI(2+4) & N/A & 1,504 \\
\hline lowest tertile & N/A & $559(37.2)$ \\
\hline middle tertile & N/A & $447(29.7)$ \\
\hline upper tertile(ERI) & N/A & $498(33.1)$ \\
\hline Smoking & & \\
\hline no & $2,359(67.8)$ & $1,042(69.3)$ \\
\hline yes & $1,119(32.2)$ & $462(30.7)$ \\
\hline Drinking & & \\
\hline ethanol grams per week(SD) & $201.7(289.2)$ & $169.7(242.5)$ \\
\hline never & $1,490(42.8)$ & $553(36.8)$ \\
\hline moderate & $1,441(41.4)$ & $460(30.6)$ \\
\hline heavy & $547(15.7)$ & $491(32.7)$ \\
\hline
\end{tabular}

\section{Evaluation of potential gender effect modification}

To examine whether gender interactions exist in the association between ERI and smoking or drinking, likelihood ratio tests for interactions were performed. In terms of the association between ERI and smoking, no statistically significant interactions were found after adjusting for age, education and marital status, work position and weekly working hours constant $(p>0.05)$. The $p$ values for the likelihood-ratio tests were 0.20 and 0.82 in Korea and Japan, respectively. For drinking, after adjusting all the covariates, no statistically significant interaction was found; the $p$ value was 0.82 in Korea and 0.19 in Japan. The complete results of gender-specific analyses are shown in Supplementary Table 1 and Table 2 (Additional File 1). Although there was no statistically significant gender interaction, the results were different between men and women; for example, the number of female smokers was quite low. Thus, the results of gender-specific analyses are shown in supplementary tables.

\section{ERI and health behaviours in Korea}

Based on Korean data (2007), the results of different adjusted models for smoking and drinking are presented in Table 3. The gender-specific association between ERI and health behaviours was also explored (see Supplementary Table 1 and Table 2, Additional File 1).

\section{Smoking}

As shown in Table 3, all the results were statistically significant $(p<0.05)$ among people who experienced the highest level of work stress (T3-high effort and low reward) compared to T1. After adjusting for age (Model 1), the OR ( $95 \% \mathrm{Cl}$ ) represents the ERI effect size on smoking behaviour, where the OR of upper ERI was 1.45 (1.22-1.73). A considerable change in the effect size of the upper 
ERI group was observed after adjusting for gender (Model 2), and the OR $(95 \% \mathrm{Cl})$ was 1.81 (1.49-2.20). Further adjustment for social and work-related covariates reduced the effects of work stress but remained statistically significant (Models 3 and 4 ).

\section{Drinking}

The effect sizes of ERI on drinking are presented in the bottom part of Table 3. When comparing moderate-alcohol consumers to non-alcohol consumers, it was found that the RRR $(95 \% \mathrm{Cl})$ of upper ERI compared to low ERI was 1.15 (0.93-1.42) in fully adjusted Model 4 , although this association was not statistically significant $(p>0.05)$. Statistically significant results were obtained when examining the association between the upper tertile of ERI and heavy drinking. The RRR $(95 \% \mathrm{Cl})$ in Model 4 was 1.43 (1.09-1.90). Additionally, gender takes major accounts for the largest change in RRRs in Model 2.

In addition, analysis, place of residence was taken into consideration. Participants were classified as living in the capital Seoul or elsewhere. The effect size of ERI did not change when the residence variable was added into the regression models. The result of the likelihood ratio test showed that residence did not play a role in the association between ERI and smoking or between ERI and drinking, as the p-value were 0.30 and 0.87 , respectively. 
Table 3

ORs $(95 \% \mathrm{Cl})$ of the association between Effort-reward Imbalance and current smokers and drinkers in Korea

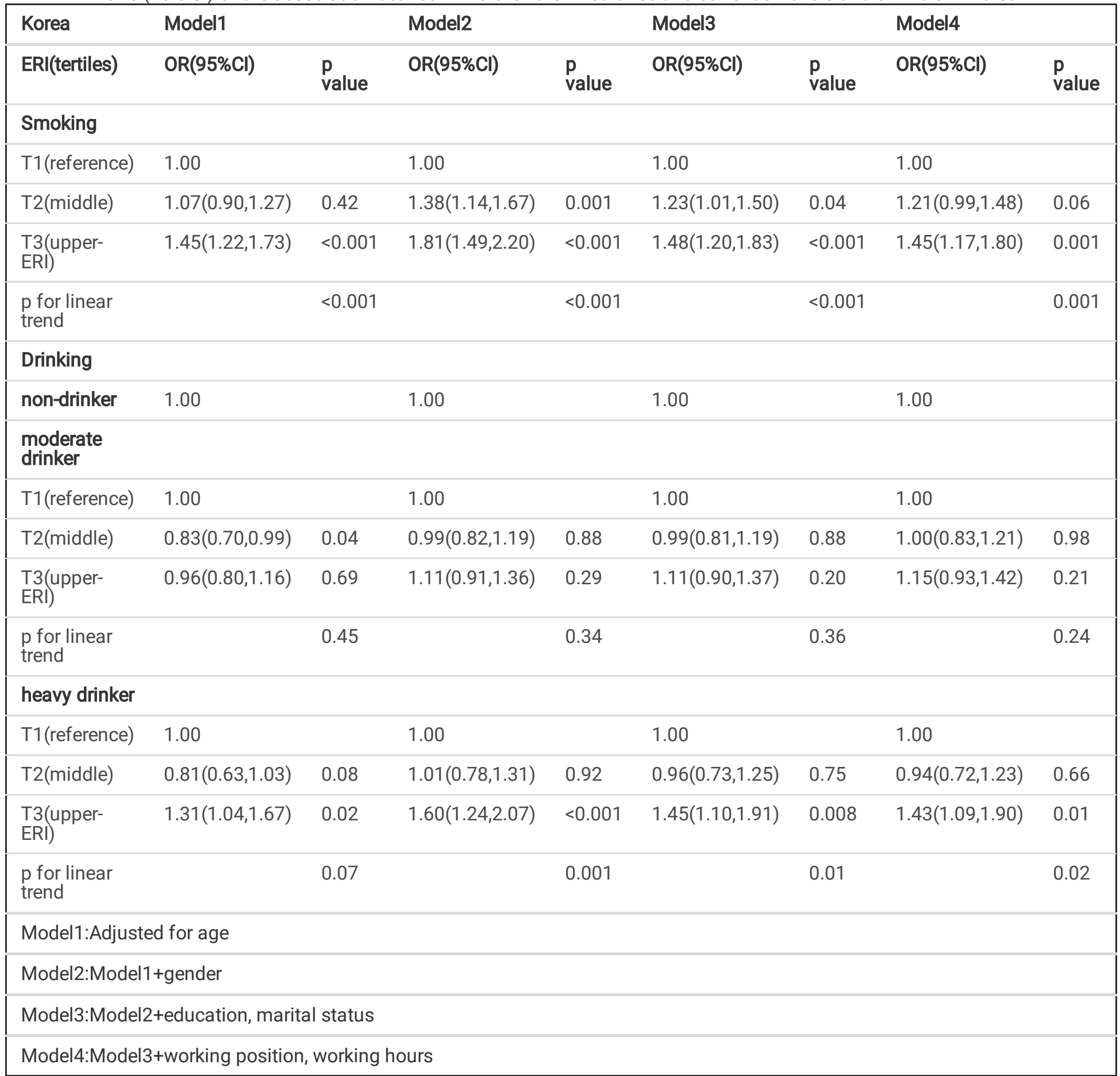

\section{ERI and health behaviours in Japan}

The Japanese analysis was based on the JSTAR data in 2007 (5 cities) and 2009 (2 cities). In the short version of the ERI model, the higher ERI group had a higher proportion of smoking individuals among Japanese people. Compared to the lowest ERI group, the proportion of heavy drinkers slightly decreased in the upper tertile from 35.3-31.1\%. Using the longer ERI model, the prevalence of smoking was the highest in the middle tertile. The characteristics of the drinking prevalence of the long ERI version were similar to those of the short version. Additionally, the ER ratios of the upper tertile (T3) in both ERI measurements had the widest range from 1.14 to 4 and from 0.93 to 3.20 , respectively. 
To compare the KLoSA and JSTAR datasets, the analytical process of JSTAR had the same sequence of adjustments of the covariates as it did in Korea. As more ERI-related questions were available in JSTAR, this study used a shorter version $(1+2$ questions, same as in Korea) to make available comparisons and a longer version of the ERI model (2+4) to perform the sensitivity analysis. The full results for smoking and drinking are presented in Tables 4 and 5. Because the Japanese female data might not be reliable, this study also tested the gender-specific association between ERI and health behaviours [15]. These results are shown in Supplementary Table 1 and Table 2 (Additional File 1).

\section{Smoking}

Table 4 shows the relationship between ERI and dichotomized smoking in Japan. To compare the results from Japan and Korea, the results using the short version of the ERI evaluation $(1+2)$ are presented in the top part of Table 4 . The ORs $(95 \% \mathrm{Cl})$ of smoking for the upper tertile versus the lowest tertile of ER ratio were 1.49 (1.12-1.98) when adjusted for age (Model 1) and 1.55 (1.15-2.08) when additionally adjusted for gender (Model 2). The magnitude and strength of the association decreased when additionally adjusted for education and marital status. ERI remained associated with smoking in a similar way as in KLoSA.

Table 4

ORs (95\% Cl) of the association between ERI and current smoking in Japan

\begin{tabular}{|c|c|c|c|c|c|c|c|c|}
\hline $\begin{array}{l}\text { Japan- } \\
\text { smoking }\end{array}$ & Model1 & & Model2 & & Model3 & & Model4 & \\
\hline ERI (tertiles) & $\mathrm{OR}(95 \% \mathrm{Cl})$ & $\mathrm{p}_{\text {value }}$ & $\mathrm{OR}(95 \% \mathrm{Cl})$ & $\mathrm{p}_{\text {value }}$ & $\mathrm{OR}(95 \% \mathrm{Cl})$ & $\begin{array}{l}p \\
\text { value }\end{array}$ & $\mathrm{OR}(95 \% \mathrm{Cl})$ & $\begin{array}{l}\mathrm{p} \\
\text { value }\end{array}$ \\
\hline \multicolumn{9}{|l|}{$\operatorname{Japan}(1+2)$} \\
\hline T1(reference) & 1.00 & & 1.00 & & 1.00 & & 1.00 & \\
\hline T2(middle) & $1.31(1.01,1.70)$ & 0.05 & $1.42(1.08,1.87)$ & 0.01 & $1.33(1.01,1.75)$ & 0.04 & $1.32(1.00,1.75)$ & 0.05 \\
\hline T3(upper-ERI) & $1.50(1.13,2.00)$ & 0.005 & $1.56(1.16,2.10)$ & 0.004 & $1.36(1.00,1.85)$ & 0.05 & $1.37(1.01,1.89)$ & 0.05 \\
\hline $\begin{array}{l}p \text { for linear } \\
\text { trend }\end{array}$ & & 0.004 & & 0.003 & & 0.04 & & 0.04 \\
\hline \multicolumn{9}{|l|}{$\operatorname{Japan}(2+4)$} \\
\hline T1(reference) & 1.00 & & 1.00 & & 1.00 & & 1.00 & \\
\hline T2(middle) & $1.49(1.13,1.96)$ & 0.004 & $1.71(1.28,2.28)$ & $<0.001$ & $1.62(1.21,2.17)$ & 0.001 & $1.59(1.18,2.14)$ & 0.002 \\
\hline T3(upper-ERI) & $1.30(0.99,1.70)$ & 0.05 & $1.31(0.99,1.73)$ & 0.06 & $1.21(0.91,1.61)$ & 0.19 & $1.17(0.87,1.58)$ & 0.29 \\
\hline $\begin{array}{l}p \text { for linear } \\
\text { trend }\end{array}$ & & 0.05 & & 0.05 & & 0.19 & & 0.29 \\
\hline \multicolumn{9}{|c|}{ Model1:Adjusted for age } \\
\hline \multicolumn{9}{|c|}{ Model2:Model1+gender } \\
\hline \multicolumn{9}{|c|}{ Model3:Model2+education, marital status } \\
\hline Model4:Mode & rking positio & kins & & & & & & \\
\hline
\end{tabular}

\section{Drinking}

According to Table 5, the relationship between ERI categorised into tertiles and drinking in Japan was different from the trend seen in Korea. When comparing people in different ERI groups, people with higher work stress were less likely to drink. Moreover, when adjusted for additional covariates, the effect size of ERI on drinking did not change much (Model 3 and Model 4). 
Table 5

RRRs $(95 \% \mathrm{Cl})$ of the association between ERI and drinking levels in Japan

\begin{tabular}{|c|c|c|c|c|c|c|c|c|}
\hline Japan-drinking & Model1 & & Model2 & & Model3 & & Model4 & \\
\hline ERI (tertiles) & $\operatorname{RRR}(95 \% \mathrm{Cl})$ & $\begin{array}{l}\mathrm{p} \\
\text { value }\end{array}$ & $\operatorname{RRR}(95 \% \mathrm{Cl})$ & $\begin{array}{l}p \\
\text { value }\end{array}$ & $\operatorname{RRR}(95 \% \mathrm{Cl})$ & $\begin{array}{l}p \\
\text { value }\end{array}$ & $\operatorname{RRR}(95 \% \mathrm{Cl})$ & $\begin{array}{l}p \\
\text { value }\end{array}$ \\
\hline \multicolumn{9}{|l|}{$\operatorname{Japan}(1+2)$} \\
\hline Non-drinker & 1.00 & & 1.00 & & 1.00 & & 1.00 & \\
\hline \multicolumn{9}{|l|}{$\begin{array}{l}\text { moderate } \\
\text { drinker }\end{array}$} \\
\hline T1(reference) & 1.00 & & 1.00 & & 1.00 & & 1.00 & \\
\hline T2(middle) & $0.74(0.55,0.99)$ & 0.04 & $0.74(0.55,1.00)$ & 0.09 & $0.77(0.56,1.04)$ & 0.09 & $0.76(0.56,1.04)$ & 0.08 \\
\hline T3(upper-ERI) & $0.90(0.65,1.24)$ & 0.50 & $0.85(0.61,1.18)$ & 0.33 & $0.92(0.65,1.30)$ & 0.63 & $0.91(0.64,1.29)$ & 0.59 \\
\hline $\begin{array}{l}p \text { for linear } \\
\text { trend }\end{array}$ & & 0.40 & & 0.26 & & 0.53 & & 0.50 \\
\hline \multicolumn{9}{|l|}{ heavy drinker } \\
\hline T1(reference) & 1.00 & & 1.00 & & 1.00 & & 1.00 & \\
\hline T2(middle) & $0.71(0.54,0.94)$ & 0.02 & $0.71(0.52,0.97)$ & 0.03 & $0.71(0.52,0.97)$ & 0.03 & $0.71(0.52,1.02)$ & 0.02 \\
\hline T3(upper-ERI) & $0.78(0.57,1.07)$ & 0.12 & $0.72(0.51,1.02)$ & 0.07 & $0.71(0.49,1.01)$ & 0.06 & $0.71(0.50,1.04)$ & 0.08 \\
\hline $\begin{array}{l}p \text { for linear } \\
\text { trend }\end{array}$ & & 0.08 & & 0.05 & & 0.04 & & 0.05 \\
\hline \multicolumn{9}{|l|}{$\operatorname{Japan}(2+4)$} \\
\hline \multicolumn{9}{|l|}{$\begin{array}{l}\text { moderate } \\
\text { drinker }\end{array}$} \\
\hline T1(reference) & 1.00 & & 1.00 & & 1.00 & & 1.00 & \\
\hline T2(middle) & $0.79(0.58,1.07)$ & 0.13 & $0.83(0.60,1.14)$ & 0.26 & $0.84(0.60,1.16)$ & 0.28 & $0.85(0.61,1.17)$ & 0.32 \\
\hline T3(upper-ERI) & $0.89(0.66,1.20)$ & 0.45 & $0.84(0.62,1.15)$ & 0.28 & $0.87(0.64,1.20)$ & 0.41 & $0.89(0.64,1.23)$ & 0.47 \\
\hline $\begin{array}{l}p \text { for linear } \\
\text { trend }\end{array}$ & & 0.44 & & 0.27 & & 0.40 & & 0.47 \\
\hline \multicolumn{9}{|l|}{ heavy drinker } \\
\hline T1(reference) & 1.00 & & 1.00 & & 1.00 & & 1.00 & \\
\hline T2(middle) & $0.75(0.56,1.02)$ & 0.07 & $0.82(0.59,1.14)$ & 0.24 & $0.80(0.57,1.11)$ & 0.18 & $0.80(0.57,1.12)$ & 0.19 \\
\hline T3(upper-ERI) & $0.78(0.58,1.05)$ & 0.10 & $0.72(0.52,0.99)$ & 0.05 & $0.71(0.51,0.97)$ & 0.04 & $0.71(0.51,0.99)$ & 0.04 \\
\hline $\begin{array}{l}p \text { for linear } \\
\text { trend }\end{array}$ & & 0.09 & & 0.04 & & 0.04 & & 0.04 \\
\hline \multicolumn{9}{|c|}{ Model1:Adjusted for age } \\
\hline \multicolumn{9}{|c|}{ Model2:Model1+gender } \\
\hline \multicolumn{9}{|c|}{ Model3:Model2+education, marital status } \\
\hline
\end{tabular}

\section{Sensitivity analysis of JSTAR}


The results of smoking sensitivity analysis are shown in the bottom part of Table 4. No statistically significant differences between the top and bottom ERI tertiles were found when a longer version of ERI was used, while the OR of smoking was significantly increased in the middle ER ratio group. In terms of drinking, the results of short version and long version ERI model evaluation presented a similar trend.

\section{Discussion}

\section{Main findings and comparison with previous studies}

The results indicate that a higher ERI level was positively associated with a higher prevalence of smoking and heavy drinking among Korean workers above 45 years old. Moreover, it was found that work-related stress was associated with smoking among Japanese people aged 50 and above. ERI was not, however, significantly associated with drinking in Japan. The Japanese results for alcohol consumption contradict some previous studies [42, 43-45]. This might be because of the small sample size and selection bias. Nonetheless, the effect size and direction of ERI were consistent with the results from previous research in non-Asian regions $[46,47]$. Moreover, the results from Japan also provide some evidence for the validity of the short version of the ERI. In both analyses of Japanese data, the results using shorter and longer versions of ERI (" $2+4$ " and " $1+2$ ") are mostly but not entirely similar.

This study also used the likelihood-ratio test to explore the potential interaction between ERI and gender factors. No gender interaction was in Korea or Japan. However, the associations between ERI and health behaviours were significant among only men. This may be because only a few women in both datasets were smokers or heavy drinkers. In any case, this result was consistent with a previous US study [48]. Gender was not an effect modifier in the relationship between work-related stress and health behaviours. Contrary to most previous observational and experimental studies conducted in Western countries [8], this study found that work-related stress might be a protective factor against heavy drinking among Japanese workers and that this type of stress was not statistically significantly associated with the outcomes among Japanese females.

People with the highest ERI levels had low odds $(\mathrm{OR}<1)$ of becoming heavy drinkers in Japan. Moreover, no significant association existed between work stress and drinking by comparing moderate drinkers to non-drinkers in Japan. In Japan and Korea, the association between work-related stress and drinking was not similar.

The following explanations account for the different results in Japan. First, occupational drinking subculture could contribute to job stress. The purpose of socialisation and career development could also make individuals more or less prone to heavy drinking [49]. In several Asian countries, such as Japan, drinking alcohol is considered an essential way of engaging in social interactions [45, 50, 51]. The difference in drinking patterns in both Japan and Korea accounts for the disparity in the results. Most drinkers in Japan are moderate drinkers, while those in Korea have a penchant to binge drinking [52-54]. Hence, in Japan, the influence of drinking culture tends to be greater than the impact of work-related stress.

However, the subculture and culture norms represent difficult elements to control in the analysis [49]. One US study illustrated that even though work-related stress had more enormous effects on males' drinking behaviours than on females' drinking behaviours, the results were usually statistically significant [48]. With a sample size of 26,946 people, this US study could be used to detect the significant association between stress and drinking [48]. In this thesis, there were few Japanese smoking and drinking cases to explore any statistically significant effect of job stress, which might be one of the limitations of this study.

\section{Strengths and limitations}

This thesis utilised the ERI model with standard questions to evaluate work stress levels. It also designed a cross-sectional study to examine the association between work stress and health behaviours in Korea and Japan. In previous research, only a few studies applied the ERI model to explore the association between work stress and health behaviours [15, 32]. Of those few studies, only a small percentage focused on Asian countries. Acquired from two reliable organisations (KEIS and RIETI), the baseline data of this study were collected nationally. These data provided a representative sample in Korea and a male sample group in Japan. Although the representation of Japanese females was not very good, it has been previously stated that JSTAR provides more useful information than other existing female-based studies [36] because many other existing studies were based on only a limited geographic area or a specific occupation or age group [54-57].

Page $13 / 21$ 
This study fills the gaps in the research regarding the association between Asian workers' stress and health behaviours. Moreover, the study sample in this project comprised elderly people over 45 years old, who were more sensitive to the experience of workrelated stress than younger people [58]. Multinomial logistic regression was applied in this project to explore the association between work stress and health behaviours, thereby providing a better way to control various potential confounders simultaneously.

However, the results of this study still have several limitations. One limitation is the small sample size of JSTAR after the selection process with the inclusion and exclusion criteria. The relationship between work-related stress and drinking behaviour might be indirectly proportional given that occupation had a potential effect modification [59]. This study, however, did not take occupation into account because of the data limitations of JSTAR. Another limitation is the methodological considerations. Due to the crosssectional nature, the results could be influenced by reporting/recall bias [60]. For instance, heavy drinkers and smokers, especially among women, may not report their real behaviours. This tendency indicates that variation in personal response tendencies existed but was difficult to control [61]. Apart from the possibility of causing outcome misclassification, it is highly likely that the effect size of work-related stress on smoking and drinking becomes underestimated [62,63].

The third limitation is that the effect of residual confounding from other risk factors, which were not available in the two datasets, might influence the association between stress and health behaviours [43]. For example, drinking subcultures, a family history of drinking alcohol, occupation type and parents' social class were reported as potential confounders in the association between job stress and smoking or drinking, a behavioural pattern that may lead to under-estimation or over-estimation of the real ORs or RRRs of the association $[46,64,65]$. For outcome data, this study used standard questions to collect smoking information but could not obtain information on drinking patterns due to JSTAR data limitations, which hindered this study from further exploring the different findings of Japanese drinking behaviour.

\section{Suggestion for further research}

This research is the first study to use the ERI model to analyse work-related stress and health behaviours in Korea and Japan simultaneously, even though non-significant results in terms of work-related stress and drinking were found in Japan due to the small sample size and reasons noted previously. Previous evidence mainly supported the theory that people with more work-related stress were more likely to become smokers and heavy drinkers in European, Australian and North American countries [17-21, 6669]. The findings of this thesis also suggest that Asian countries may have the same consistent trend of ERI-smoking association found in other regions around the world $[8,70]$. By and large, this study fills the gap in this area of knowledge. In terms of the ERIdrinking association, significant results were found in Koreans and Japan. Therefore, in future research, it is pertinent to identify other datasets in Korea and Japan, evaluate associations to see whether results are consistent within national boundaries, and investigate whether any study has better alcohol data of drinking patterns to test the ERI-drinking association.

Furthermore, longitudinal studies based on a larger sample size are recommended by taking more possible confounders under control to explore the causality and clarify the relationship between work-related stress and health behaviours. Moreover, when utilising the ERI model to evaluate work-related stress levels, more data should be collected regarding questions related to extrinsic effort or work reward dimensions.

\section{Policy implications}

The data obtained from this study show that senior employees (aged 45 years and above in Korea and Japan) who live in a heavy ERI working environment are more likely to smoke. The results of this study show that Korean people are more likely to become heavy drinkers. Reducing the work-related stress of employees may have a significant impact on improving their healthy behaviours. Given that workers in Asian countries experience a similar level of work-related stress found among employees in the West, intervention methods could be learned from Western countries.

Moreover, this study advises relevant government agencies to carry out interventions focused on occupational exposures, especially work stressors. Research has shown that the workplace has a considerable casual influence on smoking cessation, and an integrated health promotion programme would go a long way in reducing work-related stress while controlling health behaviours $[61,71]$. Based on the ERI model, work-related stress could also be mitigated by interventions in extrinsic efforts and work reward aspects. Policies should be implemented to control the long work time and excessive work, which would help guarantee reasonable

Page $14 / 21$ 
periods of rest [72]. Apart from that, welfare policies need to be improved to enhance job security. The performance appraisal system also needs continuous improvement to provide appropriate evaluation and wages for employees [73, 74]. Implementing these recommendations would assist elderly Japanese and Korean workers in enjoying the dividends of working in a healthy and balanced effort-reward work environment.

\section{Conclusion}

Overall, after accounting for available covariates, it was found that a higher work stress expressed by a short version of the ERI was positively associated with a higher prevalence of smoking and heavy drinking among senior workers over 45 years old in Korea but was negatively associated with the prevalence of heavy drinking in Japan. The results also indicated that the effects of work stress were not significantly modified by gender. Moreover, the ERI-smoking association was similar in Korea and Japan. The ERI-drinking association, however, was different in these two countries. This was because work stress was a risk factor in Korea but a protective factor in Japan. Based on these findings, this paper recommends that governments enhance the balance between extrinsic efforts and work rewards in Asian countries. Doing so may improve the health behaviours, particularly smoking behaviour, of workers and accelerate social and economic development.

\section{Declarations}

\section{Ethics approval and consent to participate}

The Korean Longitudinal Study of Ageing (KLoSA) received approval from the National Statistical Office (Approval number: 33602 ) and the Institutional Review Board (IRB) of the Korea National Institute for Ethics Policy. The JSTAR survey was conducted by the Research Institute of Economy, the Research Institute of Economy, Trade and Industry Trade and Industry (RIETI), Hitotsubashi University, and the University of Tokyo, Japan. Data from KLoSA and JSTAR are publicly available with all data anonymized. This study also received approval for the secondary use of the KLOSA and JSTAR data. All methods in this study were carried out in accordance with the relevant guidelines and regulations. Since the KLoSA and JSTAR databases have been released to the public for scientific use and no experimental treatment was conducted on either human or animal subjects in this study, ethical approval was not required for the study.

\section{Consent for publication}

Not applicable.

\section{Availability of data and materials}

The KLoSA data that support the findings of this study are available from Korea Employment Information Service (KEIS), but restrictions apply to the availability of these data, which were used under licence for the current study and so are not publicly available. Data are, however, available from the authors upon reasonable request and with permission of KEIS.

The JSTAR data that support the findings of this study are available from the Research Institute of Economy, Trade and Industry (RIETI), but restrictions apply to the availability of these data, which were used under licence for the current study and so are not publicly available. Data are, however, available from the authors upon reasonable request and with permission of RIETI.

\section{Competing interests}

The authors declare that they have no competing interests.

\section{Funding}

Not applicable.

\section{Authors' contributions}


TC and HP designed this study. TC wrote the first draft of the manuscript, prepared the analysis and interpreted the data. HP helped with the analysis. All authors were involved in writing the manuscript, gave critical comments on multiple versions, and approve its final version.

\section{Acknowledgements}

Not applicable.

\section{References}

1. Ganster D, Rosen C. Work Stress and Employee Health. Journal of Management. 2013;39(5):10851122. doi:10.1177/0149206313475815

2. Kouvonen A. Work stress, smoking status, and smoking intensity: an observational study of 46190 employees. Journal of Epidemiology \& Community Health. 2005;59(1):63-69. doi:10.1136/jech.2004.019752

3. Puddephatt JA, Jones A, Gage SH, Fear NT, Field M, McManus S, et al. Associations of alcohol use, mental health and socioeconomic status in England: Findings from a representative population survey. Drug and Alcohol Dependence. $2021 ; 219$. doi:10.1016/j.drugalcdep.2020.108463

4. Richardson DP, Lovegrove JA. Nutritional status of micronutrients as a possible and modifiable risk factor for COVID-19: A UK perspective. [Online] British Journal of Nutrition. 2021. p. 678-684. doi:10.1017/S000711452000330X

5. Viswesvaran C, Sanchez J, Fisher J. The Role of Social Support in the Process of Work Stress: A Meta-Analysis. Journal of Vocational Behavior. 1999;54(2):314-334. doi:10.1006/jvbe.1998.1661

6. Siegrist J, Rödel A. Work stress and health risk behavior. Scandinavian Journal of Work, Environment \& Health. 2006;32(6):473481. doi:10.5271/sjweh.1052

7. De Jonge J, Bosma H, Peter R, Siegrist J. Job strain, effort-reward imbalance and employee well-being: a large-scale crosssectional study. Social Science \& Medicine. 2000;50(9):1317-1327. doi:10.1016/S0277-9536(99)00388-3

8. Kouvonen A, Kivimäki M, Virtanen M, Heponiemi T, Elovainio M, Pentti J et al. Effort-reward imbalance at work and the cooccurrence of lifestyle risk factors: cross-sectional survey in a sample of 36,127 public sector employees. BMC Public Health. 2006;6(1). doi:10.1186/1471-2458-6-24

9. Siegrist J, Lunau T, Wahrendorf M, Dragano N. Depressive symptoms and psychosocial stress at work among older employees in three continents. Globalization and Health. 2012;8(1):27. doi:10.1186/1744-8603-8-27

10. Karasek R. Job Demands, Job Decision Latitude, and Mental Strain: Implications for Job Redesign. Administrative Science Quarterly. 1979;24(2):285. doi:10.2307/2392498

11. Wemken G, Janurek J, Junker NM, Häusser JA. The impact of social comparisons of job demands and job control on wellbeing. Applied Psychology: Health and Well-Being. 2021;13(2): 419-436. doi:10.1111/aphw.12257

12. Hwang WJ, Hong OS, Kang DR. Psychometric Testing of the Effort-Reward Imbalance-Short Form Among Blue-Collar Workers Employed in Small Industrial Settings in Korea. Workplace Health and Safety. 2018;66(12). doi:10.1177/2165079918786296

13. Cho SI, Eum KD, Choi B, Paek D, Karasek R. Social class, job insecurity and job strain in Korea. Scandinavian Journal of Work, Environment \& Health. 2008;34(6), 60-65.

14. Siegrist J. Adverse health effects of high-effort/low-reward conditions. Journal of Occupational Health Psychology. 1996;1(1):27-41. doi:10.1037/1076-8998.1.1.27

15. Siegrist J, Starke D, Chandola T, Godin I, Marmot M, Niedhammer I et al. The measurement of effort-reward imbalance at work: European comparisons. Social Science \& Medicine. 2004;58(8):1483-1499. doi:10.1016/S0277-9536(03)00351-4

16. Payne N, Jones F, Harris P. Employees' perceptions of the impact of work on health behaviours. Journal of Health Psychology. 2012;18(7):887-899. doi:10.1177/1359105312446772

17. Green K, Johnson J. The effects of psychosocial work organization on patterns of cigarette smoking among male chemical plant employees. American Journal of Public Health. 1990;80(11):1368-1371.

18. Head J, Stansfeld SA, Siegrist J. The psychosocial work environment and alcohol dependence: a prospective study. Occup Environ Med. 2004;61:219-224. doi:10.1136/oem.2002.005256

Page 16/21 
19. Colell E, Sánchez-Niubò A, Benavides FG, Delclos GL, Domingo-Salvany A. Work-related stress factors associated with problem drinking: A study of the Spanish working population. American Journal of Industrial Medicine. 2014;57(7): 837-846. doi:10.1002/ajim.22333

20. Amano H, Fukuda Y, Kawachi I. Is Higher Work Engagement Associated with Healthy Behaviors? A Longitudinal Study. Journal of Occupational and EnvironmentalMedicine.2020;62(3):87-93. doi:10.1097/JOM.0000000000001804

21. Cheng Y, Park J, Kim Y, Kawakami N. The recognition of occupational diseases attributed to heavy workloads: experiences in Japan, Korea, and Taiwan. International Archives of Occupational and Environmental Health. 2011;85(7):791-799. doi:10.1007/s00420-011-0722-8

22. Yeh H. Job Demands, Job Resources, and Job Satisfaction in East Asia. Social Indicators Research. 2014;121(1):47-60. doi:10.1007/s11205-014-0631-9

23. Lee K, Lim H. Work-related Injuries and Diseases of Farmers in Korea. Industrial Health. 2008;46(5):424-434. doi:10.2486/indhealth.46.424

24. Lee J, Lee HJ, Hong Y, Shin YW, Chung S, Park J. Risk Perception, Unhealthy Behavior, and Anxiety Due to Viral Epidemic Among Healthcare Workers: The Relationships With Depressive and Insomnia Symptoms During COVID-19. Frontiers in Psychiatry. 2021;12. doi:10.3389/fpsyt.2021.615387

25. Kawakami N, Araki S, Haratani T, Hemmi T. Relations of Work Stress to Alcohol Use and Drinking Problems in Male and Female Employees of a Computer Factory in Japan. Environmental Research. 1993;62(2):314-324. doi:10.1006/enrs.1993.1116

26. Jung Y, Oh J, Huh S, Kawachi I. The Effects of Employment Conditions on Smoking Status and Smoking Intensity: The Analysis of Korean Labor \& Income Panel 8th-10th Wave. PLOS ONE. 2013;8(2):e57109. doi:10.1371/journal.pone.0057109

27. Ota A, Yasuda N, Okamoto Y, Kobayashi Y, Sugihara Y, Koda S et al. Relationship of Job Stress with Nicotine Dependence of Smokers-A Cross-Sectional Study of Female Nurses in a General Hospital. Journal of Occupational Health. 2004;46(3):220224. DOI: $10.1539 /$ joh. 46.220

28. Kawakami N, Haratani T. Epidemiology of Job Stress and Health in Japan: Review of Current Evidence and Future Direction. Industrial Health. 1999;37(2):174-186. DOI: 10.2486/indhealth.37.174

29. Jang T, Kim H, Lee H, Myong J, Koo J. Long Work Hours and Obesity in Korean Adult Workers. Journal of Occupational Health. 2013;55(5):359-366. DOI: 10.1539/joh.13-0043-OA

30. Tsutsumi A, Kayaba K, Yoshimura M, Sawada M, Ishikawa S, Sakai K et al. Association between job characteristics and health behaviors in Japanese rural workers. International Journal of Behavioral Medicine. 2003;10(2):125-142. DOI: 10.1207/S15327558IJBM1002_03

31. Kawakami N, Tsutsumi A, Haratani T, Kobayashi F, Ishizaki M, Hayashi T et al. Job Strain, Worksite Support, and Nutrient Intake among Employed Japanese Men and Women. Journal of Epidemiology. 2006;16(2):79-89. DOI: 10.2188/jea.16.79

32. Nomura K, Nakao M, Tsurugano S, Takeuchi T, Inoue M, Shinozaki Y et al. Job stress and healthy behavior among male Japanese office workers. American Journal of Industrial Medicine. 2010;53(11):1128-1134.DOI: 10.1002/ajim.20859

33. Lallukka T, Lahelma E, Rahkonen O, Roos E, Laaksonen E, Martikainen P et al. Associations of job strain and working overtime with adverse health behaviors and obesity: Evidence from the Whitehall II Study, Helsinki Health Study, and the Japanese Civil Servants Study. Social Science \& Medicine. 2008;66(8):1681-1698. DOI: 10.1016/j.socscimed.2007.12.027

34. Oshio T, Tsutsumi A, Inoue A. The association between job stress and leisure-time physical inactivity adjusted for individual attributes: evidence from a Japanese occupational cohort survey. Scandinavian Journal of Work, Environment \& Health. 2016;228-236. DOI: 10.5271/sjweh.3555

35. Fukuda Y, Nakamura K, Takano T. Socioeconomic Pattern of Smoking in Japan: Income Inequality and Gender and Age Differences. Annals of Epidemiology. 2005;15(5):365-372.DOI: 10.1016/j.annepidem.2004.09.003

36. Ichimura H, Hashimoto H, Shimizutani S. Japanese Study of Aging and Retirement: JSTAR First Results 2009 Report: Contents/Chapter 1 Introduction. [online]. 2009. [Accessed 22 June 2021]. Available from: http://hdl.handle.net/10086/17551

37. Karasek R, Brisson C, Kawakami N, Houtman I, Bongers P, Amick B: The Job Content Questionnaire (JCQ): an instrument for internationally comparative assessments of psychosocial job characteristics. J Occup Health Psychol. 1998;3:322-355. DOI: 10.1037/1076-8998.3.4.322

Page $17 / 21$ 
38. Fransson E, Nyberg S, Heikkilä K, Alfredsson L, Bacquer D, Batty G et al. Comparison of alternative versions of the job demandcontrol scales in 17 European cohort studies: the IPD-Work consortium. BMC Public Health. 2012;12(1). DOI: 10.1186/14712458-12-62

39. Min J, Lee K, Park J, Cho S, Park S, Min K. Social Engagement, Health, and Changes in Occupational Status: Analysis of the Korean Longitudinal Study of Ageing (KLoSA). PLoS ONE. 2012;7(10):e46500. DOI: 10.1371/journal.pone.0046500

40. Siegrist J, Wege N, Pühlhofer F, Wahrendorf M. A short generic measure of work stress in the era of globalization: effort-reward imbalance. International Archives of Occupational and Environmental Health. 2008;82(8):1005-1013. DOI: 10.1371/journal.pone.0046500

41. Devaux M, and F. Sassi, Alcohol consumption and harmful drinking: Trends and social disparities across OECD countries. [online]. OECD Health Working Papers, OECD Publishing: Paris. 2015;79 [Accessed 22 June 2021]. Available from: http://dx.doi.org/10.1787/5js1qwkz2p9s-en

42. Hiro H, Kawakami N, Tanaka K, Nakamura K. Association between job stressors and heavy drinking: Age differences in male Japanese workers. Industrial Health. 2007;45(3). doi:10.2486/indhealth.45.415

43. Ikeda A, Iso H, Toyoshima H, Fujino $Y$, Mizoue T, Yoshimura T et al. Marital status and mortality among Japanese men and women: the Japan Collaborative Cohort Study. BMC Public Health. 2007;7(1). DOI: 10.1186/1471-2458-7-73

44. Morikawa Y, Nakagawa H, Miura K, Soyama Y, Ishizaki M, Kido T et al. Shift work and the risk of diabetes mellitus among Japanese male factory workers. Scandinavian Journal of Work, Environment \& Health. 2005;31(3):179-183. DOI: $10.5271 /$ sjweh.867

45. Kitano H, Chi I, Rhee S, Law C, Lubben J. Norms and alcohol consumption: Japanese in Japan, Hawaii and California. Journal of Studies on Alcohol. 1992;53(1):33-39. DOI: 10.5271/sjweh.867

46. Kouvonen A, Kivimaki M, Elovainio M, Vaananen A, De Vogli R, Heponiemi T et al. Low organisational justice and heavy drinking: a prospective cohort study. Occupational and Environmental Medicine. 2008;65(1):44-50. DOI: 10.1136/oem.2007.032755

47. Ota A, Masue T, Yasuda N, Tsutsumi A, Mino Y, Ohara H. Association between psychosocial job characteristics and insomnia: an investigation using two relevant job stress models-the demand-control-support (DCS) model and the effort-reward imbalance (ERI) model. Sleep Medicine. 2005;6(4):353-358. DOI: 10.1016/j.sleep.2004.12.008

48. Dawson D, Grant B, Ruan W. The Association between stress and drinking: Modifying effects of gender and vulnerability. Alcohol and Alcoholism. 2005;40(5):453-460. DOI: 10.1093/alcalc/agh176

49. Becker SJ, Marceau K, Hernandez L, Spirito A. Is it Selection or Socialization? Disentangling Peer Influences on Heavy Drinking and Marijuana Use Among Adolescents Whose Parents Received Brief Interventions. Substance Abuse: Research and Treatment. 2019;13:1-9. doi:10.1177/1178221819852644

50. Lu W, Xu J, Taylor AW, Bewick BM, Fu Z, Wu N, et al. Analysis of the alcohol drinking behavior and influencing factors among emerging adults and young adults: A cross-sectional study in Wuhan, China. BMC Public Health. 2019;19(1). doi:10.1186/s12889-019-6831-0

51. Wendt S, Mohr C, Wang M, Haverly S. Proximal Predictors of Alcohol Use among Japanese College Students. Substance Use and Misuse. 2018;53(5): 763-772. doi:10.1080/10826084.2017.1365086

52. Makimoto, K. Drinking patterns and drinking problems among Asian-Americans and Pacific Islanders. Alcohol health and research world. 1998;22:270-275.

53. Lee K. Gender-specific relationships between alcohol drinking patterns and metabolic syndrome: the Korea National Health and Nutrition Examination Survey 2008. Public Health Nutrition. 2012;15(10):1917-1924. D0I: 10.1017/S136898001100365X

54. Eum K, Li J, Lee H, Kim S, Paek D, Siegrist J et al. Psychometric properties of the Korean version of the effort-reward imbalance questionnaire: a study in a petrochemical company. International Archives of Occupational and Environmental Health. 2007;80(8):653-661. DOI: 10.1007/s00420-007-0174-3

55. McCreary D, Sadava S. Stress, drinking, and the adverse consequences of drinking in two samples of young adults. Psychology of Addictive Behaviors. 1998;12(4):247-261. DOI: 10.1037/0893-164X.12.4.247

56. Boo S, Oh H. Women's Smoking: Relationships Among Emotional Labor, Occupational Stress, and Health Promotion. Workplace Health and Safety. 2019;67(7): 361-370. doi:10.1177/2165079918823214

Page 18/21 
57. Nakata A, Takahashi M, Ikeda T, Hojou M, Nigam J, Swanson N. Active and passive smoking and depression among Japanese workers. Preventive Medicine. 2008;46(5):451-456. DOI: 10.1016/j.ypmed.2008.01.024

58. Lighthall N, Gorlick M, Schoeke A, Frank M, Mather M. Stress modulates reinforcement learning in younger and older adults. Psychology and Aging. 2013;28(1):35-46. DOI: 10.1037/a0029823

59. Carayon P. A longitudinal test of Karasek's Job Strain model among office workers. Work \& Stress. 1993; 7(4):299-314. DOI: $10.1080 / 02678379308257070$

60. Prayle AP, Hurley MN, Smyth AR. Compliance with mandatory reporting of clinical trial results on ClinicalTrials.gov: Cross sectional study. BMJ (Online). 2012;344(7838). doi:10.1136/bmj.d7373

61. Albertsen K, Hannerz H, Borg V, Burr H. Work environment and smoking cessation over a five-year period. Scandinavian Journal of Public Health. 2004;32(3):164-171. DOI: 10.1080/14034940310017779

62. Cho H, Khang Y, Jun H, Kawachi I. Marital status and smoking in Korea: The influence of gender and age. Social Science \& Medicine. 2008;66(3):609-619. DOI: 10.1016/j.socscimed.2007.10.005

63. Borland R, Partos T, Cummings K. Systematic Biases in Cross-sectional Community Studies may Underestimate the Effectiveness of Stop-Smoking Medications. Nicotine \& Tobacco Research. 2012;14(12):1483-1487. DOI: 10.1093/ntr/nts002

64. Pan A, Schernhammer ES, Sun Q, Hu FB. Rotating night shift work and risk of type 2 diabetes: Two prospective cohort studies in women. PLoS Medicine. 2011;8(12). doi:10.1371/journal.pmed.1001141

65. Macleod J. Are the effects of psychosocial exposures attributable to confounding? Evidence from a prospective observational study on psychological stress and mortality. Journal of Epidemiology \& Community Health. 2001;55(12):878-884. DOI: 10.1136/jech.55.12.878

66. Jachens L, Houdmont J, Thomas R. Effort-Reward Imbalance and Heavy Alcohol Consumption Among Humanitarian Aid Workers. Journal of Studies on Alcohol and Drugs. 2016;77(6):904-913. DOI: 10.15288/jsad.2016.77.904

67. Otten F. Job stress and smoking in the Dutch labour force. The European Journal of Public Health. 1999;9(1):58-61. DOI: 10.1093/eurpub/9.1.58

68. Angrave D, Charlwood A, Wooden M. Long working hours and physical activity. Journal of Epidemiology and Community Health. 2015;69(8):738-744. DOI: 10.1136/jech-2014-205230

69. Popham F. Leisure time exercise and personal circumstances in the working age population: longitudinal analysis of the British household panel survey. Journal of Epidemiology \& Community Health. 2006;60(3):270-274.

70. Magnusson Hanson L, Westerlund H, Goldberg M, Zins M, Vahtera J, Hulvej Rod N et al. Work stress, anthropometry, lung function, blood pressure, and blood-based biomarkers: a cross-sectional study of 43,593 French men and women. Scientific Reports. 2017;7(1).

71. Sorensen G, McLellan D, Dennerlein J, Pronk N, Allen J, Boden L et al. Integration of Health Protection and Health Promotion: Rationale, Indicators, and Metrics. Journal of Occupational and Environmental Medicine. 2013;55:S12-S18.

72. Park S, Lee JH, Lee W. The Effects of Workplace Rest Breaks on Health Problems Related to Long Working Hours and Shift Work among Male Apartment Janitors in Korea. Safety and Health at Work. 2019;10(4): 512-517.

doi:10.1016/j.shaw.2019.10.003

73. Brown M, Benson J. Managing to Overload?. Group \& Organization Management. 2005;30(1):99-124.

74. Ivancevich J, Napier H, Wetherbe J. Occupational stress, attitudes, and health problems in the information systems professional. Communications of the ACM. 1983;26(10):800-806.

\section{Figures}




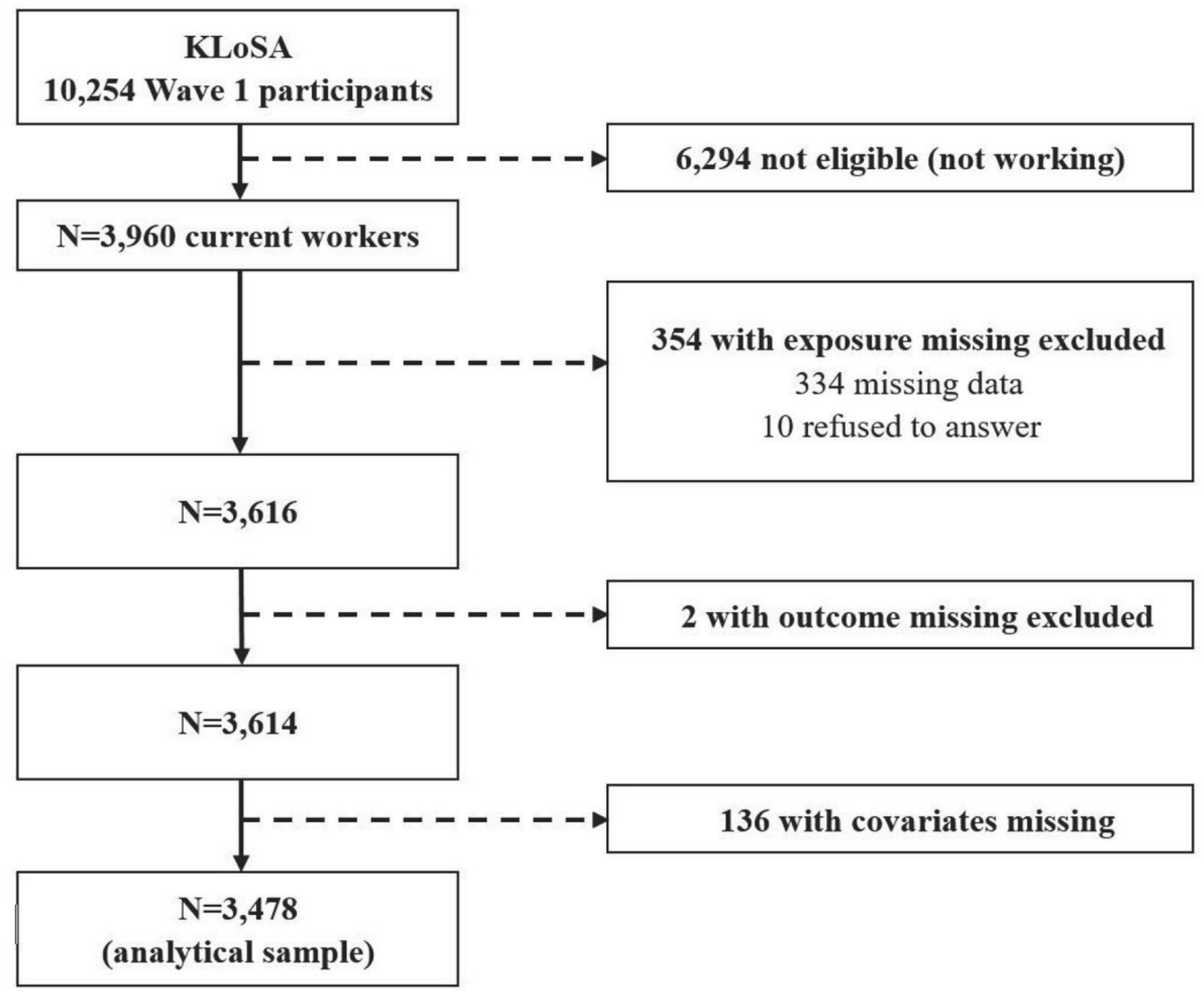

Figure 1 Flow chart of the Korean cross-sectional study sample selection

Figure 1

See image above for figure legend. 


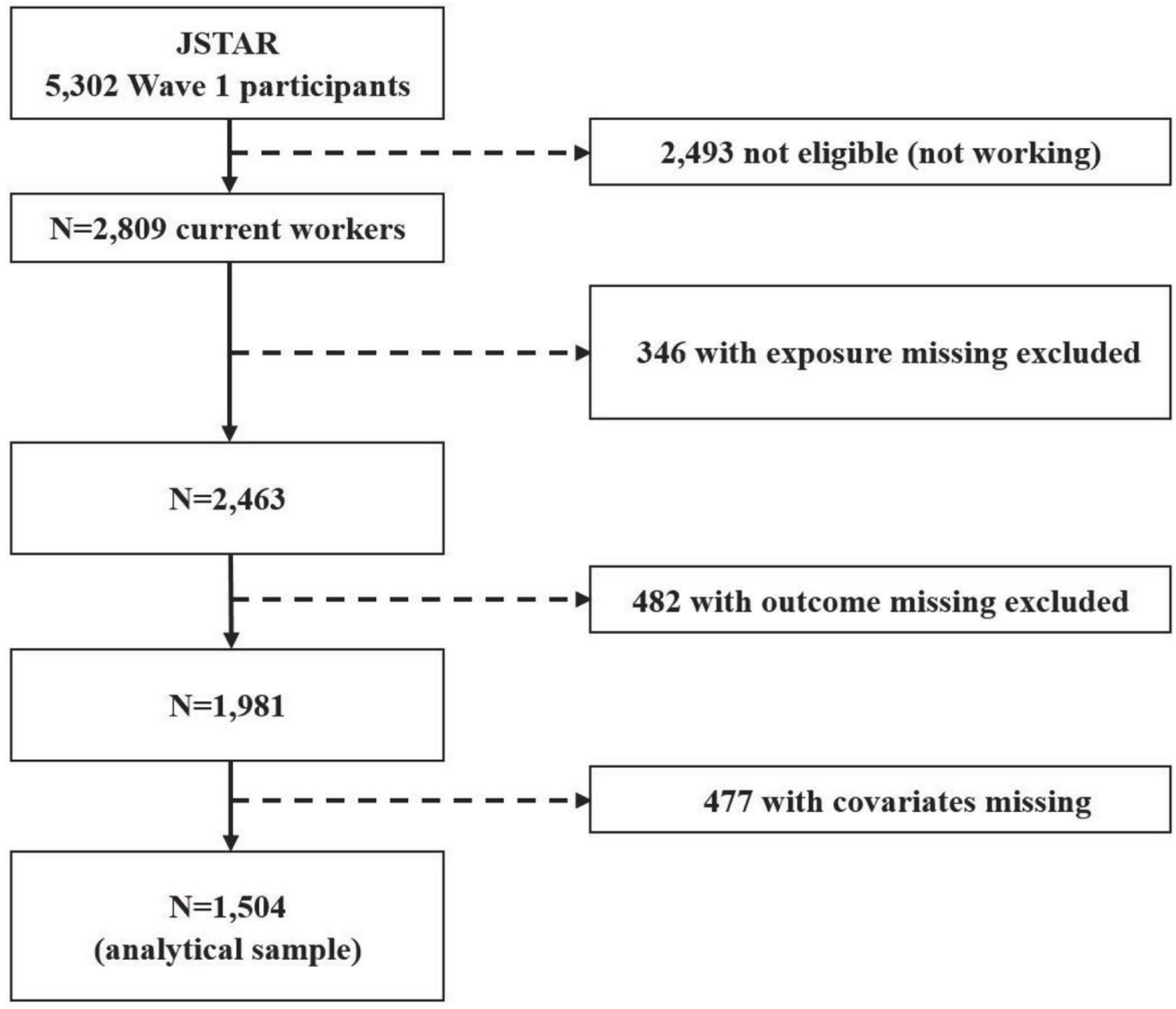

Figure 2 Flow chart of the Japanese cross-sectional study sample selection

Figure 2

See image above for figure legend.

\section{Supplementary Files}

This is a list of supplementary files associated with this preprint. Click to download.

- SupplementalTables.docx 